\title{
Study on the social integration and family relocation decision of urban migrants based on Structural Equation Model
}

\author{
Chen Hongsheng ${ }^{1,}$, ,Wang Xingping ${ }^{2, b}$ and Zhu zhenjun ${ }^{3, c}$
}

${ }^{1}$ School of Architecture, Southeast University, Nanjing 210096,China

${ }^{2}$ School of Architecture, Southeast University, Nanjing 210096,China

${ }^{3}$ School of Transportation, Southeast University, Nanjing 210096,China

ahongsheng.chen2006@163.com, bwxpsx2000@sina.com, c1814428217@qq.com

Keywords: Social integration; Family relocation decision; Structure equation model

Abstract: In the background of rapid urbanization in China, it is an important task to improve the level of social integration and solve the problem of discrete distribution of floating family members. A Structural Equation Model (SEM) of family relocation decision related to rural factors, urban factors and social integration was built in the paper to examine the influence mechanism of social integration and family relocation decision in Shanghai. It is found that floating populations integrate themselves into urban life with a positive attitude which is also the future choice of their children. However, compared to rural life, nearly half of those floating people do not feel real happy. In addition, the higher income of floating population is, the higher level of social integration will be, which will also enhance the chance of rural areas to offer economic supports, thus contributing to the decision of moving to the city. Simultaneously, the existence of rural contracted land provides the condition to return. The greater economic value of the contract is, the higher possibility of returning home. Therefore, in order to improve social integration and the quality of urbanization, the government should put an emphasis on the melioration of floating population employment, increase family income and establish basic public service for floating families.

\section{Introduction}

Since the entrance of the new normal stage of development, with the economic slowdown, the importance of the healthy development of urban and rural areas has been emphasized a lot. Especially in these years, the new urbanization in China is a national strategy which requires a higher level, more balanced and more fair process of urbanization. Different from the traditional development patterns simply pursuing the growth of economy where the urbanization of land is faster than the population urbanization, the new urbanization calls for the acceleration of the urbanization of those floating agricultural population known as migrant workers, floating population thus achieve a synergetic development between urban and rural areas or between the society and economy. Since the reform and opening up, the floating population has contributed a lot to the prosperity of the urban economy in China, supporting the first accumulation of the development of labor-intensive industries in coastal areas during the process of industrialization, which lays the foundation for regional industrial upgrading, transfer and adjustment. However, under the special development background in China, barriers, such as household registration, housing, basic public service facilities and social security system, restricting the urbanization of those floating people still exist, which leads to the long-term circular flow of migrants between urban and rural places and few people's integration into city. Simultaneously, a variety of 
"heterogeneous" social space has been formed because of the huge population flow in China, such as "urban village"[1,2]. Through the construction of the "non-normal" urban space, the urban floating population is able to adapt to the city. In recent years, in the context of the slowdown of urban growth, urban capital began to shift to rural areas. The growth of rural places starts to be concerned, and the remarkable success of the beautiful rural construction of some areas makes the "rural renaissance" more likely[3]. Moreover, under the stimulus of national policies and measures like the promotion of agricultural development, farmland circulation and farmer transfer, etc. great changes have taken place in the development environment of rural areas in China. In summary, under the background of transformation occurring in the development environment of both urban and rural places, the "pull" and "push" force of the two places will also change. Based on the analysis above, we discussed the social integration of floating population and their household relocation decisions, exploring the influencing mechanism from the urban and rural aspects.

"Social integration", which is also called the integration of urban society, is a state of urban residents reflecting the adaptation and social integration to urban life[4].Over the 30 years of reform and opening-up, the scale of floating population in China's big cities and the urban social space caused by the floating population phenomenon have been gradually stable. The floating population group status and their gathering space attracted many researchers' attention, thus related researches on social integration kept increasing. Ren Yuan proposed that the unity of subjective expectation of floating population and the objective acceptance of urban society is of great importance in the process of social integration[5]. Urban social integration is a complex concept meaning that different scholars can analyze and evaluate the process and the status from different perspectives. For instance, Zhang Wenhong, etc. believed that social integration of urban new immigrants contains four dimensions like cultural integration, psychological integration, identity integration and economic integration[6], while Li Peilin, etc. found that there was no essential difference in social integration state between new generation migrant works and older ones[7]. Similarly, the influencing factors of social integration is also the focus of the academia, for example, there has been some researches proving that housing, whether or not living with family and basic public services, etc. have great impact on social integration of migrant workers [8-10].

During the early 30 years of reform and opening up, "city" is the main carrier of the modernization process in China, which provided great preponderances of resources and policy. Moreover, the flow of resources, the policy advantages contributed to the rapid growth of economy. While at the same time, the development gap between urban and rural areas kept widening, population in rural areas swarming into cities thus forming the seasonal flow path (like the bird migration) between urban and rural places under the urban-rural dual structure for the flowing population namely the migrant workers, which had a profound influence on the society, both positive and negative. In the explanation of rural family migration phenomenon, the push and pull force theory is one of the most commonly used analytical tools[11] among which rural economic, social and cultural issues like the policy of price scissors, the decline of rural areas and the collapse of local society are the important push of rural population's outflow while more employment opportunities, higher income and the busting urban life seem to be the pull. However, under the background of urban-rural dual structure based on the household registration system, most of the flowing population has not achieved real integration into cities[12]. Traditional rural family structure has been hard-hit in recent years. More and more discrete families are arising, leading to many severe social problems such as the left-behind women, children and the elderly, which has become an important issue in the process of urbanization that we have to face and solve[13].Since the entering of the new normal development stage, China has increased the support for "agriculture, rural areas and farmers". The development 
of rural areas began to speed up gradually and the development environment started to change as well. The rural governance has been put on the agenda of China's modernization[14], thus contributing to tremendous improvement of rural land value[15], increasing population backflow [16,17], and changes of existing urban-rural relationship.

In conclusion, the fact that rural population flowing from rural areas to urban areas is the result of the joint effect of rural factors and urban factors. Generally speaking, the migration to urban areas of rural families is the gradual process from a single individual to a whole family. Therefore, the integration of urban migrants has a direct impact on their family relocation decision. Based on the theory mentioned above, we did a further research on the relationship between family relocation decision and some influencing factors like rural factors, urban factors and the integration to urban life which provides theory support for researches on urban-rural development and migrant family. In this paper, we first introduce the research method we employed and the research data we obtained. After that we carry out an empirical research based on data of questionnaire conducted in Shanghai. At last, we make a conclusion and have some discussion.

\section{Research methods}

In the paper, structural equation model is employed as the main analysis instrument which integrates two statistical methods: factor analysis and path analysis. The effect of independent variables on the dependent variables can be obtained by different combination of latent variables. As a kind of confirmatory analysis method, SEM is usually adopted in the empirical researched on theoretical correction, empirical justification[18], which has been widely utilized in the researches on places identify of new migrants[19], urban community resident's travel behavior[20], settlement intention of rural migrants[21], relationship between spatial elements of city-regions[22], etc. It can be seen that SEM has an advantage over discussing relationship between numerous elements, especially the compound concepts (latent variables) like "place identify", "settlement intention", "urban growth" and so on. In this paper, "social integration", family relocation decision" are kinds of these compound concepts. Therefore, we employ SEM to discuss the impact on floating population's social integration and their family's relocation decision caused by urban factors, trying to explore the influencing mechanism under the background of rapid family urbanization. In addition, the software AMOS 17.0 is employed to modeling and analysis in our study.

A data of Shanghai a typical example of China's big city, that is, the data of the questionnaire of dynamic monitoring of the floating population in megalopolis of Beijing, Shanghai and Guangzhou conducted by the national population and family planning commission in 2012 is been used in our study. Floating population aged 15-59 years old and living in Shanghai for more than a month is the research object of this paper. The stratified multi-stage PPS sampling method is used. Specifically, a total of 14993 valid data is obtained covering 17 districts (countries) which include three stages: towns-streets, village committee and individuals. Generally speaking, rural factors, urban factors, social integration and family relocation decision are regarded as latent variables and among them rural factors mainly focus on the rural land and its economic value; urban factors mainly refer to housing, urban income and spending and community attitudes; social integration mostly reflect in the settlement intention and social integration of floating population; family relocation decision includes living form and future expectations of their children. 


\section{Empirical analysis}

\section{Basic situation of floating population in Shanghai and information of their social integration and family relocation decision}

Based on the 14993 questionnaires, information of individual characteristics, rural factors and urban factors of the respondents has been statistically analyzed. According to individual characteristics, these migrants in Shanghai have relatively stable jobs. $92.4 \%$ of them have changed their job less than twice. As to the age structure, $68.8 \%$ of the migrants are $21-40$ years with low level of education but high married proportion. Only $16.9 \%$ of them have completed college degree or above but $79.5 \%$ of them are already married. In addition, $62.4 \%$ of our respondents have no rural contracted land and $37.6 \%$ of them still keep the rural contracted land among who $91.0 \%$ have less than $5 \mathrm{mu}$ of land, which is consistent with the situation that each person has about $1.3 \mathrm{mu}$ of land. Moreover, $70.1 \%$ of them get less than 500 yuan annual income of the rural contracted land, which proves that the income of the land economic is relatively low. In terms of urban factors, family local income of these migrants is mostly at the middle and low grade, that is, those less than 3000 yuan a month counts for $68.7 \%$. Compared with the data of household urban spending, the urban living costs for migrants are high that $26.5 \%$ of them spend over 7001 yuan a month. Note that, on the housing spending, the rate of monthly rent below 500 yuan is $64.2 \%$ which is related to income spending levels and living conditions.

"Dwelling time", "dwelling form" and "development of offspring" are chosen to be representative indicators of family relocation decision. Among them, the distribution of dwelling time of migrant in Shanghai are relatively homogeneous, the proportion of "less than 2 years" is $28.1 \%$ while "more than 7 years" is $38.9 \%$.As for the dwelling form, most of the migrants choose to live with family or relatives, which count for $76.1 \%$.About the development of offspring, $96.0 \%$ of the respondents want their children to stay in the city while only $4.0 \%$ of them hope their children can go back to rural home, which somehow reflects that city is still the choice of most migrant families. We choose "settlement intention", "happiness" and "social integration" as the representative indicators of social integration. $80.0 \%$ of respondents intend to live in Shanghai for a long time and $9.5 \%$ of them would like to take an active part in their community. However, it should be noted that as much as $41.6 \%$ of the respondents think that compared the old days in rural home, their new life here in the modern city is not so much happy. To some certain, the above data reflects that compared to rural areas, city can provide more development opportunities and higher life quality, which is pretty attractive to those migrants. Nevertheless, it brings in higher living costs and pressure, which leads to the unhappiness. It is a kind of contradictory to choose the big city to realize the family urbanization.

\section{Analysis of the influencing mechanism of migrants' social integration and relocation decision in Shanghai}

\section{Modeling and variables}

The influencing mechanism of migrants' social integration and relocation decision is investigated using SEM, and the relationship between the two is also analyzed. We focus on the urban and rural influencing factors. Besides, there exists a relationship between social integration and urban-rural relocation, so we include urban factors, rural factors, family relocation decision, social integration and the corresponding measured variables in the our measurement model, and then establish the structure model with these factors. Among them, we choose dwelling time, living form and development of offspring to reflect family relocation decision. Land (the contracted land) and income based on land are contained in rural factors. According to existing study on rural areas, 
income from the contracted land is the important decision basis of migrants [23,24]. Rent, household income, household spending and community attitude are investigated in urban factors. Under the background of high housing prices in big cities, housing has become a significant influencing factor of migrants' settlement intention [25,26]. In addition, community attitude mainly reflects the rejection of city. Social integration is mirrored by settlement intention for a long time (at least five years), social integration, happiness (compared with rural life).Based on literature review, hypothesis of the structure equation model is shown in Fig.1.

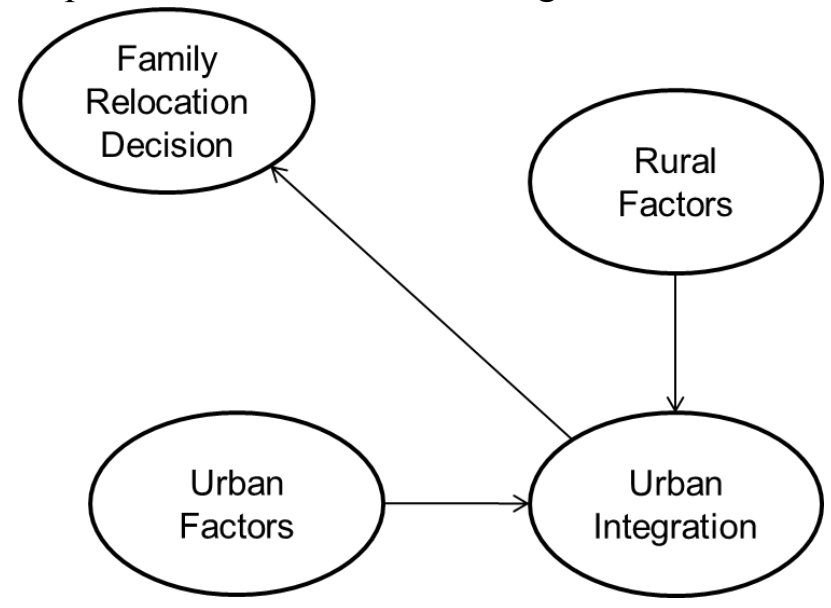

Fig.1 Hypothesis of the structure equation model

\section{Model modification}

AMOS 17.0 is used to estimate the parameter of hypothesis model, the results is shown in Tab.1. In the structure model of hypothesis, the path coefficient from rural factors to social integration did not reach the significance, which means that we need to further modify the model. The revised structure model is shown in Fig.2, in which urban factors, rural factors all have impact on family relocation decision and social integration of those migrants. Tab.1shows the new parameter estimation of the revised model in which all parameters have reached the significance. Moreover, DOF is $60, \chi^{2}$ is 4871.3 and RMSEA, NFI, CFI are relatively $0.073,0.862,0.864$, which signify a good fit of model $[19,27]$. The results of SEM are acceptable. 
Tab.l Estimation of the variables in the structure equation model

\begin{tabular}{|c|c|c|c|c|c|c|c|c|c|c|c|c|c|c|c|}
\hline \multirow{3}{*}{$\begin{array}{l}\text { Model } \\
\text { SEM }\end{array}$} & \multirow{2}{*}{\multicolumn{3}{|c|}{ Path }} & \multicolumn{5}{|c|}{ Parameter Estimation of Hypothetical Model } & \multirow{2}{*}{\multicolumn{2}{|c|}{ Path }} & \multicolumn{5}{|c|}{ Parameter Estimation ofModified Model } \\
\hline & & & & \multirow{2}{*}{$\begin{array}{c}\text { Estimate } \\
0.217\end{array}$} & \multirow{2}{*}{$\begin{array}{l}\text { S.E. } \\
0.008\end{array}$} & \multirow{2}{*}{$\begin{array}{c}\mathrm{t} \\
27.764\end{array}$} & \multirow{2}{*}{$\begin{array}{c}\mathrm{P} \\
-\infty * *\end{array}$} & \multirow{2}{*}{$\begin{array}{c}\text { Standardized } \\
\text { Estimate } \\
0.585\end{array}$} & & & \multirow{2}{*}{$\begin{array}{c}\text { Estimate } \\
0.182\end{array}$} & \multirow{2}{*}{$\begin{array}{l}\text { S.E. } \\
0.008\end{array}$} & \multirow{2}{*}{$\begin{array}{c}\mathrm{t} \\
22.704\end{array}$} & \multirow{2}{*}{$\begin{array}{l}\mathrm{p} \\
\cdots\end{array}$} & \multirow{2}{*}{$\begin{array}{c}\text { Standardized } \\
\text { Estimate } \\
0.372\end{array}$} \\
\hline & Social integration & $\leftarrow$ & Urban factor & & & & & & $\ldots$ & Urban factor & & & & & \\
\hline & & $\leftarrow$ & Rural factor & -0.016 & 0.011 & -1.519 & 0.129 & -0.017 & $\ldots$ & Rural factor & -0.084 & 0.015 & -5.409 & $\cdots$ & -0.067 \\
\hline & \multirow{3}{*}{$\begin{array}{l}\text { Family relocation } \\
\text { decision }\end{array}$} & \multirow{3}{*}{$\leftarrow$} & \multirow{3}{*}{$\begin{array}{c}\text { Social } \\
\text { integration }\end{array}$} & \multirow{3}{*}{1.157} & \multirow{3}{*}{0.040} & \multirow{3}{*}{28.859} & \multirow{3}{*}{$\cdots$} & \multirow{3}{*}{0.910} & $<$ & Rural factor & 0.091 & 0.016 & 5.764 & $\cdots$ & 0.069 \\
\hline & & & & & & & & & $<$ & Social integration & 0.484 & 0.026 & 18.445 & $\cdots$ & 0.460 \\
\hline & & & & & & & & & $\leftarrow$ & Urban factor & 0.236 & 0.010 & 24.120 & $\cdots$ & 0.460 \\
\hline \multirow[t]{3}{*}{$\begin{array}{c}\text { Model } \\
1\end{array}$} & $\begin{array}{c}\text { Area of Contracted } \\
\text { Land }\end{array}$ & $<$ & \multirow{3}{*}{ Rural factor } & 1.000 & - & - & - & 0.464 & $<-$ & \multirow{3}{*}{ Rural factor } & 1.000 & - & - & - & 0.467 \\
\hline & Income of Contracted & - & & 7.971 & 0.161 & 49.652 & $\cdots$ & 0.964 & - & & 7.851 & 0.156 & 50.474 & $\cdots$ & 0.955 \\
\hline & Contracted Land & $<$ & & 2.040 & 0.036 & 57.024 & $\cdots$ & 0.783 & $<$ & & 2.045 & 0.036 & 57.118 & $\cdots$ & 0.789 \\
\hline \multirow{4}{*}{$\begin{array}{c}\text { Model } \\
2\end{array}$} & Rent & $<-$ & \multirow{4}{*}{ Urban factor } & 1.000 & - & - & - & 0.435 & $<-$ & \multirow{4}{*}{ Urban factor } & 1.000 & - & - & - & 0.421 \\
\hline & Household Income & $\leftarrow$ & & 2.999 & 0.069 & 43.396 & w.. & 0.778 & - & & 3.184 & 0.075 & 42.360 & $\cdots$ & 0.801 \\
\hline & Household Spending & $\leftarrow$ & & 1.949 & 0.044 & 43.888 & w. & 0.730 & $<$ & & 1.960 & 0.045 & 43.098 & $\cdots$ & 0.712 \\
\hline & Community Attitude & $<$ & & 0.053 & 0.006 & 9.301 & $\ldots$ & 0.088 & $\leftarrow$ & & 0.049 & 0.006 & 8.393 & $\ldots$ & 0.079 \\
\hline \multirow{3}{*}{$\begin{array}{c}\text { Model } \\
3\end{array}$} & Settlement Intention & - & \multirow{3}{*}{$\begin{array}{l}\text { Social } \\
\text { integration }\end{array}$} & 1.000 & - & - & - & 0.457 & _. & & 1.000 & - & - & - & 0.583 \\
\hline & Happiness & $\leftarrow$ & & 1.020 & 0.037 & 27.423 & $\ldots$ & 0.378 & $\leftarrow$ & Social integration & 0.918 & 0.036 & 25.181 & $\cdots$ & 0.434 \\
\hline & Social Integration & $\leftarrow$ & & 0.223 & 0.013 & 16.979 & ..4 & 0.197 & $<-$ & & 0.234 & 0.012 & 19.717 & $\cdots$ & 0.264 \\
\hline Model & Dwelling Form & $\leftarrow$ & Family & 1.000 & - & - & - & 0.545 & $<$ & & 1.000 & - & - & - & 0.574 \\
\hline & Children's Residence & $<-$ & & 0.145 & 0.010 & 15.289 & $\ldots$ & 0.173 & $<$ & decision & 0.122 & 0.009 & 13.941 & $\ldots$ & 0.153 \\
\hline & Dwelling Time & $\leftarrow$ & & 2.665 & 0.082 & 32.454 & $\cdots$ & 0.494 & $\leftarrow$ & & 2.474 & 0.073 & 33.892 & $\cdots$ & 0.483 \\
\hline
\end{tabular}




\section{Model explanation}

Based on analysis above, we can come to the conclusion that the fitting degree of the SEM is relatively good, all the path coefficients in the model and the standardized factor load coefficients are meaningful. The standardized factor load coefficient reflects relationship between observation variables and the corresponding latent variables. Fig. 2 shows some significant observation variables and the standardized factor load coefficients (others are presented in Tab.1). Among them, in the model of urban factors, urban incomes (monthly total revenue of local family) and urban spending (monthly total spending of local family) fully explain the urban factors with coefficients of 0.801 , 0.712. In the model of rural factors, coefficients of income of contracted land and whether to have contracted land are relatively $0.955,0.789$, which are pretty persuasive. The model of social integration is explained by settlement intention better whose standardized factor load coefficient is 0.583. While in the model of family decision, standardized factor load coefficient of living form is 0.574 which better explains family decision. To sum up, the variables mentioned above better explain the latent variables of urban factors, rural factors and social integration, meaning that the three latent variables embodied by those factors have a direct or indicate impact on family decision.

As to the structure of model, urban factor and rural factor relatively point to family decision and social integration while social integration points to family decision. Moreover, all the paths have reached the significance, but the relationships between variables reflected by path coefficients are different. Path coefficient reflects the influencing intensity of latent variables. As we can see in Fig.2, urban factors and rural factors have direct influences on family decision and social integration, while urban factor has a high influential intensity. Rural factor has less impact on social integration and family decision which is also much more balanced, moreover, it has a negative influence on social integration which on the contrary has an obviously positive impact on family decision. Specifically, if urban factor changes about 1, family decision will change about 0.640 while social integration will change about 0.372 both positively; if rural factor changes about 1 , family decision will change about 0.069 positively while social integration will change about 0.067 ; if social integration changes about 1 , family decision will change about 0.460 positively, which reflect that for migrants and their families, the higher urban incomes and spending are, the higher level of social integration it will be which means that they are more willing and more adaptive to live in the city for a long time. Rural contracted land and incomes provide favorable conditions for the returning of migrants. The greater economic value of contracted land, the stronger attention of rural places will be, which may even lower social integration of migrants and eventually lead to the returning of them. As to family decision, the better social integration, higher urban incomes and more support of rural areas will provide more economic support, thus contributing to the family decision of settlement intention namely to move from rural areas to realize family reunion. Therefore, urban factor is the main influencing reason of relocation decision. 


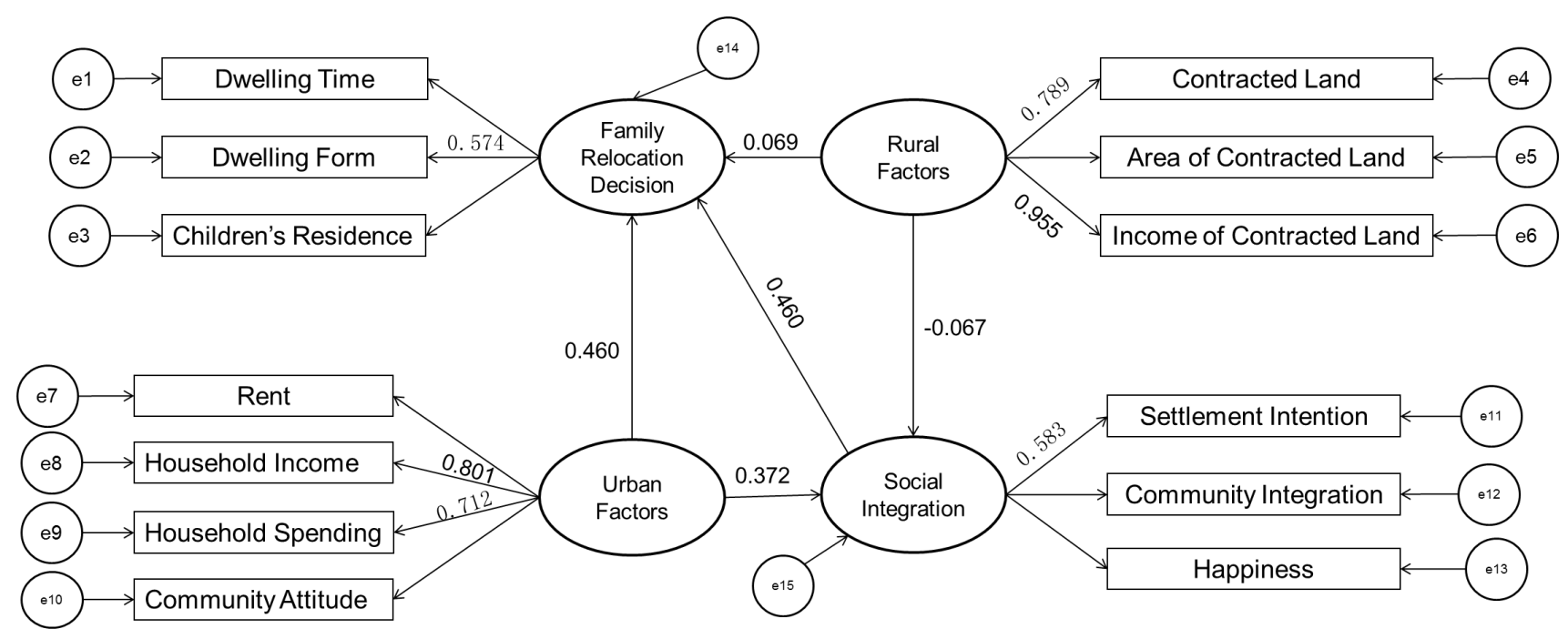

Fig.2 Results of the structure equation model

\section{Conclusions}

It has been an important task in the next phase of urbanization in our country to enhance the level of social integration, solve the family discretization problem of migrants. Research shows that most migrants try to actively integrate into urban life and their offspring seems to be more likely to choose city as their future choice. However, compared with rural life, under the high pressure of high urban living costs, almost half of migrants do not feel so much happy. As to the influencing factors, for migrants and their families, the higher income they have, the higher level of social integration and settlement intention it will be, which will bring more economic support from rural areas contributing to the decision of settlement in city. Besides, rural contracted land provides favorable conditions for the returning of migrants. The greater the economic value contracted land provides, the stronger the attention of rural places will get and the higher possibility it will be for migrants to return to rural areas. However, because of the high incomes and high living costs in Shanghai, the economic support from rural areas has few impacts on social integration and relocation decision of the migrants which is mainly influenced by urban factor. Therefore, except promoting social integration, enhancing quality of urbanization, level of employment should be improved to increase family incomes of migrants. Furthermore, equal basic public service covering migrants and their families should also be established to further promote social integration and social mobility.

\section{References}

[1] Xiang Biao. What is community[J]. Sociological Studies, 1998(6):56-64.

[2] Li Zhigang, Liu Ye, Chen Hongsheng. Characteristic, mechanism, and spatiality of neo-migrants homeplace-based communities in China: A case study of Hubei village, Guangzhou[J]. Geographical Research, 2011, 30(10):1910-1920.

[3] Wang Xingping. Family Based Coupled Urbanization: A New Perspective of New Urbanization Research[J]. Modern urban research, 2014(12):88-94.

[4] Chen Hongsheng, Li Zhigang. The Research on Social Integration of Social Housing Community in Urban China-—A Case Study of Guangzhou[J]. City Planning Review, 2015, 39(9):33-39. 
[5] Ren Yuan, Qiao Nan. Social Integration for Migrants: Process, Measurement and Determinants[J]. Population Research, 2010, 34(2): 11-20.

[6] Zhang Wenhong, Lei Kaichun. The Urban New Immigrants' Social Inclusion: Internal Structure, Present Situation and Influential Factors[J]. Sociological Studies, 2008(5): 117-141+244-245.

[7] Li Peilin, Tian Feng. A Cross Generational Comparison of the social cohesion of migrant workers in China[J]. Chinese Journal of Socjology, 2012(5):1-24.

[8] Han Junqiang. Housing and Urban Iintegration of Migrant Workers: Survey in Wuhan City[J]. Social Sciences in China, 2013(2):118-125.

[9] Yu Yunjiang, Sun Bindong, Sun Xu. The Level of Urban Social Integration Based on ESDA: A Case Study of Shanghai[J]. Human Geography, 2014, 29(2):123-128.

[10] Chen Hongsheng, Wang Xingping. Improving Public Service for Rural Migrant Workers[J]. Planners, 2015, 31(3):11-16.

[11] Zhang Zhiliang, Zhang Tao, Zhang Qian. The theory and application of the push and pull mechanism of migration[J].Chinese Journal of Population Science, 1997(2):36-42.

[12] An Analysis of Push and Pull Factors in the Migration of Rural Workers in China[J].Social Sciences in China, 2003(1):125-136.

[13] Wang Xingping. Family Based Coupled Urbanization: A New Perspective of New Urbanization Research[J]. Modern urban research, 2014(12):88-94.

[14] Liu Yansui, Liu Yu, Zhai Rongxin. Geographical Research and Optimizing Practice of Rural Hollowing in China[J]. Acta Geographica Sinca, 2009, 64(10):1193-1202.

[15] Chen Hao, Zhang Jingxiang, Chen Hongsheng. The Transformation of Land Dividend Under the Perspective of New Urbanization[J]. Economic Geography, 2015, 35(4):1-8.

[16] Liu Yungang, Yan Tingting. Types of the Return Migrations from Megacities to local cities in China: A Case Study of Zhumadian's Return Migrants[J]. Geographical Research, 2013, 32(7):1280-1290.

[17] Wang Zicheng, Zhao Zhong. Dynamic Choice of Peasant Workers Migration Patterns: Outflow, Return or remigration[J]. Management World, 2013(1):78-88.

[18] Structure Equation Mode: Operation and Application[M]. Chongqing: Chongqing University Press, 2010.

[19] Zhao Xiangguang, Li Zhigang. Study on Place Identity of New Migrants in Urban China[J]. City Planning Review, 2013,37(12):22-29.

[20] Cao Xiaoshu, Lin Qiang. A SEM-based Study on Urban Community Resident's Travel Behavior in Guangzhou[J]. Acta Geographica Sinca, 2011, 66(2):167-177.

[21] Wang Yujun. Settlement Intention of Rural Migrants in Chinese Cities[J]. Population Research, 2013, 37(4):19-32.

[22] Shi Jin, Huang Zhiji, He Canfei. On the Coupling Relationship Between Economic Space, Resources and the Environment, and Land Use of China's 16 Major City-Regions[J]. Urban Development Studies, 2013, 20(7):26-34. 
[23] He Xuefeng. The Logic of Land Rights[M]. Beijing: China University of Political Science and Law Press, 2010.

[24] Chen Huiguang, Liu Zhongyuan, Shi Xiaoping. The Role of Land Rights and Interests on Migrant Workers'Urban-rural Migration Decision[J]. Issues in Agricultural Economy, 2012, 33(7):70-77.

[25]Li Zhigang. Housing Conditions, Patterns and Mechanisms of Second Generation Migrants in Urban China: A Case Study of Six Large Cities[J]. Acta Geographica Sinica, 2012, 67(2): 189-200.

[26] Chen Hongsheng, Li Li, Li Zhigang. A Review on the Studies of Urban Housing in China amid Rapid Urbanization: Based on the Analysis of Core Periodicals[J]. City Planning Review, 2014, 38(5):65-77.

[27] Bentler P M, Dudgeon P. Covariance Structure Analysis: Statistical Practice, Theory, and Directions[J]. Annual Review of Psychology, 1996, 47(1): 563-592. 